\title{
PENGARUH PENAMBAHAN PARTIKEL CHROMIUM TERHADAP KEKERASAN ALUMINA YANG MENGANDUNG 20\%BERAT SILIKA
}

\author{
Subardi \\ Jurusan Teknik Mesin STTNAS Yogyakarta \\ Jl. Babarsari, Catur Tunggal Depok, Sleman, Yogyakarta 55281, \\ Telp. (0274) 485390, 486986 Faks. (0274) 487249
}

\begin{abstract}
ABSTRAK
Tujuan penelitian ini untuk mengetahui pengaruh penambahan partikel chromium terhadap kekerasan alumina yang mengandung 20\% berat silica. Komposit matrik alumina keramik $\left(\mathrm{Al}_{2} \mathrm{O}_{3}\right)$ yang mengandung $20 \%$ berat silica $\left(\mathrm{SiO}_{2}\right)$ diperkuat dengan 0, 3, 6, 9, 12 dan $15 \%$ volume partikel chromium (Cr) telah dibuat dengan metode pressureless sintering. Masing-masing komposisi di-mixing dengan proses basah (dengan alkohol) selama 5 jam, dikeringkan selama 24 jam pada temperatur kamar dan dilanjutkan dengan mixing kering selama 5 jam. Pembuatan spesimen berbentuk silindris (diameter $d=15 \mathrm{~mm}$; tebal $t=5 \mathrm{~mm}$ ) dilakukan dengan uniaxial-pressing pada tekanan $120 \mathrm{MPa}$. Sintering dilakukan di lingkungan argon dengan laju pemanasan $3^{\circ} \mathrm{C} /$ menit sampai $800^{\circ} \mathrm{C}$ dan ditahan selama 30 menit, kemudian dinaikkan dengan laju pemanasan $5^{\circ} \mathrm{C}$ /menit hingga temperatur $1450^{\circ} \mathrm{C}$ dan ditahan selama 60 menit. Pendinginan dilakukan di dalam furnace dengan cara mematikan power kefurnace. Kondisi komposist mengalami tegangan radial tarik sedangkan tegangan tangensial tekan. Pengujian kekerasan Vickers dengan beban 153,2 N menunjukkan penurunan kekerasan bahan dari $892 \mathrm{MPa}$ (tanpa penguat $\mathrm{Cr}$ ) menjadi $329 \mathrm{MPa}$ (komposit dengan $15 \%$ volume Cr). Porositas pada permukaan keramik komposit $\mathrm{Al}_{2} \mathrm{O}_{3}-\mathrm{SiO}_{2} / 12 \% \mathrm{Vol}$ Cr pada suhu 1450 masih cukup besar.
\end{abstract}

Kata Kunci: alumina, chromium, pressureless sintering, kekerasan.

\section{PENDAHULUAN}

Keramik merupakan salah satu material teknik yang sedang dikembangkan secara berkelanjutan dan semakin luas pemakaiannya di bidang teknik maupun industri. Aplikasi keramik di bidang teknik khususnya permesinan antara lain pompa, alat potong, sudu turbin gas, katub dan lainnya (Somiya 1989). Keramik memiliki sifat-sifat fisis yang baik antara lain: titik lebur tinggi, tahan terhadap temperatur tinggi, tahan terhadap gesekan, tahan korosi, daya hantar panas rendah, densitas relatif rendah, modulus elastisitas tinggi dan koefisien muai panjang rendah. Namun demikian disamping memiliki keunggulan tersebut keramik juga mempunyai kelemahan yaitu bersifat getas dan ketangguhan retaknya rendah.

Alumina $\left(\mathrm{Al}_{2} \mathrm{O}_{3}\right)$ merupakan salah satu jenis keramik yang mempunyai sifat fisik yang stabil, dengan keunggulan tahan panas dan korosi, titik cair $2050^{\circ} \mathrm{C}$ sedangkan koefisien muai panas alumina dengan kemurnian $96 \%$ adalah $6,7 \times 10^{-6} /{ }^{\circ} \mathrm{C}$. Chromium adalah jenis logam tahan korosi, ulet, memiliki ketahanan panas yang baik. Chromium mempunyai koefisien muai panas $(\alpha)$ sebesar $9 \times 10^{-6} /{ }^{\circ} \mathrm{C}$, titik cair 
$1875^{\circ} \mathrm{C}$, berat jenis ( ) $7,2 \mathrm{gr} / \mathrm{cm}^{3}$ dan modulus elastisitas (E) sebesar $279 \mathrm{GPa}$ (Surdia dan Saito, 1992).

Pembuatan komposit matrik keramik (Ceramic Matrix Composites) merupakan salah satu cara untuk mengurangi kelemahankelemahan keramik baik mengunakan penguat berupa partikel logam maupun keramik.

\section{TINJAUAN PUSTAKA}

Kondo, dkk (1999) meneliti komposit $\mathrm{ZrO}_{2} / \mathrm{Ni}$ dimana bahan matriknya adalah $\mathrm{ZrO}_{2}$ yang mengandung $3 \mathrm{~mol} \% \mathrm{Y}_{2} \mathrm{O}_{3}$ (dikenal dengan $3 \mathrm{Y}^{-} \mathrm{ZrO}_{2}$ ) dan bahan penguatnya adalah Ni dengan 1, 2, 3, 5, 7 dan $10 \%$ volume. Pembuatan komposit tersebut dilakukan dengan hot -pressing dengan tekanan $30 \mathrm{MPa}$ selama 1 jam dalam lingkungan argon, temperatur sinter $1500^{\circ}$ dan $1600^{\circ} \mathrm{C}$. Densitas diukur dengan teori Archimedes. Kekerasan dievaluasi dengan pengujian Vickers dengan beban $196 \mathrm{~N}$ selama 15 detik, secara bersamaan ketanggguhan retak ditentukan dengan metode indentation fracture.

Ade Indra (2004) meneliti komposit $\mathrm{Al}_{2} \mathrm{O}_{3}$ yang mengandung $20 \%$ berat silica menggunakan partikel penguat nikel (Ni) dengan komposisi 0 , $3,6,9,12$, dan $15 \%$ volume. Pembuatan komposit tersebut dilakukan dengan proses pressureless sintering di lingkungan argon. Pengukuran densitas menggunakan teori Archimedes dan hasilnya sebesar $92,41 \%$ diperoleh pada spesimen dengan temperatur $1425^{\circ} \mathrm{C}$. Pengujian kekerasan Vickers dengan beban 153,2 N menunjukkan penurunan kekerasan bahan dari $824 \mathrm{MPa}$ (komposit dengan $0 \%$ volume $\mathrm{Ni}$ ) menjadi $540 \mathrm{MPa}$ (komposit dengan 15\% volume Ni). Pengujian fracture toughness dilakukan dengan metode single-edge notched beam (SENB) menunjukkan peningkatan harga fracture toughness dari $0,76 \mathrm{MPa} \cdot \mathrm{m}^{1 / 2}$ pada komposit dengan $0 \%$ vol Ni menjadi $1,03 \mathrm{MPa}$ $\mathrm{m}^{1 / 2}$ pada komposit dengan $12 \% \mathrm{Ni}$. Pengujian kekuatan bending dilakukan dengan metode four point bending test memberikan peningkatan bending dari 32,0 MPa pada komposit dengan $0 \%$ volume Ni menjadi 37,0 MPa pada komposit dengan 9 dan $12 \%$ volume Ni. Peningkatan ketangguhan retak terjadi dengan mekanisme crack deflection, percabangan retak (crack branching) dan crack bridging.

\section{LANDASAN TEORI}

Bahan keramik adalah senyawa nonorganik yang tersusun dari unsur logam dan bukan logam, ketahanan keramik terhadap slip lebih baik, sehingga keramik lebih keras tetapi selalu kurang ulet dibandingkan dengan bahan logam atau polimer. Pembuatan komposit matrik keramik yang diperkuat dengan partikel logam banyak dilakukan karena logam memiliki sifat yang lebih ulet dari pada keramik.

Secara umum pembuatan keramik dilakukan melalui beberapa tahap yaitu: mixing (pencampuran); pressing (pengempaan) dan sintering ( pamanasan)

Proses mixing bahan keramik dan partikel logam penguat biasanya dilakukan dengan dua cara yaitu proses basah dan proses kering. Pada proses basah digunakan alkohol hal ini karena alkohol tidak bereaksi dengan partikel logam selama pencampuran berlangsung. Setelah proses pencampuran dilanjutkan dengan proses pressing untuk pembentukan green body. Proses pressing (pengempaan) dapat dilakukan dengan cara uniaxial pressing maupun isostatic pressing.

Sintering yaitu memanaskan green body di dalam furnace (dapur pemanas), selama sintering mengalami beberapa tahapan perubahan fisik material sampai titik leleh (Ryshkewitch, 1960).

Perbedaan koefisien muai panas antara partikel logam penguat dengan matrik keramik akan menyebabkan tegangan sisa pada interface antara partikel logam dengan matrik keramik. Jika $a_{m}>a_{p}$ maka pada interface akan terjadi tegangan radial tekan dan tegangan tangensial tarik namun jika $\mathrm{a}_{\mathrm{m}}<\mathrm{a}_{\mathrm{p}}$ maka yang terjadi pada interface adalah tegangan radial tarik dan tegangan tangensial tekan.

Microcrack dapat terjadi pada proses pendinginan dari suhu sintering, hal ini disebabkan karena perbedaan koefisien muai panas antara matrik dengan partikel penguat. Micro- 
crack ini dapat menyebabkan percabangan retak (crack branching) yang mendistribusikan energi regangan dari suatu permukaan patah, sehingga menurunkan faktor intensitas tegangan (stess intensity factor) pada ujung retak utama (principal crack tip). Percabangan retak dapat meningkatkan ketangguhan retak karena energi yang dibutuhkan untuk merambatkan banyak retak lebih besar dari pada merambatkan sebuah retak utama (Chawla,1993). Microcrack dapat dipengaruhi oleh ukuran partikel (particle size). Jika jari-jari partikel jauh lebih kecil dari jarijari kritis partikel $(\mathrm{r}<\mathrm{rc})$ maka komposit dalam keadaan stabil dan tidak terjadi microcrack, jika jari-jari partikel mendekati jari-jari kritis ( $\mathrm{r}$ rc) maka pada komposit dapat terjadi stress induced microcracking dan jika jari-jari partikel jauh lebih besar dari jari-jari kritis partikel $(\mathrm{r}>>\mathrm{rc})$ akan terjadi spontaneous microcracking.

Jari-jari kritis partikel dapat dihitung dengan persamaan (Davidge dan Green, 1968).

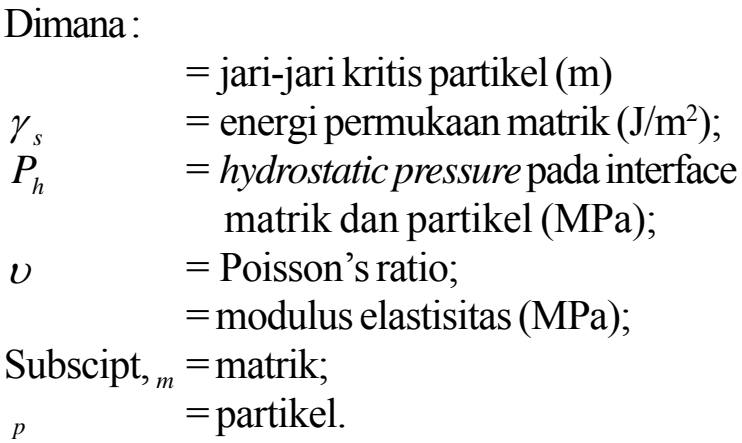

Termal stress merupakan faktor yang perlu diperhatikan karena sifat getas yang dimiliki oleh bahan keramik. Thermal stress pada komposit keramik dapat disebabkan oleh beberapa faktor antara lain : gradien suhu saat pendinginan cepat, sifat anisotropis bahan dan $\alpha$ fasa kedua jauh lebih besar dari matrik keramik. Jika ada sebuah partikel bulat pada sebuah infinite matrix, maka besarnya thermal stress dapat dihitung dengan persamaan (Barsoum, 1997).

$$
\begin{aligned}
\text { Dimana: } & \\
\sigma_{\text {rad }} & =\text { tegangan radial }(\mathrm{MPa}) \\
\sigma_{\tan } & =\text { tegangan tangensial }(\mathrm{MPa}) ; \\
& =\text { koefisien muai panas }\left(/{ }^{\circ} \mathrm{C}\right) ; \\
& =\text { beda suhu }\left({ }^{\circ} \mathrm{C}\right) ; \\
& =\text { Poisson's ratio; } \\
& =\text { modulus elastisitas }(\mathrm{MPa}) ; \\
& =\text { jari-jari partikel }(\mathrm{m}) ; \\
& =\text { jarak dari interface } k e \text { titik yang } \\
r & \text { ditinjau }(\mu \mathrm{m}) ; \text { Subscipt }, \\
& =\text { matrik } \\
& \text { partikel. }
\end{aligned}
$$

Pada komposit matrik keramik yang diperkuat dengan partikel berbentuk bulat yang terdistribusi di dalam matrik keramik, perlu dipertimbangkan tegangan radial $\left(\sigma_{\mathrm{rad}}\right)$ dan tegangan tangensial ( ${ }_{\text {tan }}$ ) pada matrik. Tegangan yang terjadi dipengaruhi oleh penambahan partikel ke dalam matrik keramik (penambahan fraksi volum partikel) yang dapat dihitung dengan persamaan berikut (Chawla,1993).

$$
\begin{gathered}
\sigma_{\tan }=-\frac{P_{h}}{1-V_{p}}\left(\frac{1}{2} \frac{R^{3}}{a^{3}}+V_{p}\right) \ldots \ldots \ldots \ldots \ldots . . . \\
P_{h} \frac{\left(\alpha_{m}-\alpha_{p}\right) \Delta T}{\left[\frac{0,5\left(1+v_{m}\right)+\left(1-2 v_{m}\right) V_{p}}{E_{m}\left(1-V_{p}\right)}+\frac{1-2 v_{p}}{E_{p}}\right] . .}
\end{gathered}
$$

$$
\begin{aligned}
& \text { Dimana } \\
& \begin{aligned}
\sigma \operatorname{rad} & =\text { tegangan radial matrik }(\mathrm{MPa}) \\
\tan & =\text { tegangan tangensial matrik }(\mathrm{MPa}) \\
& =\text { jari-jari partikel }(\mathrm{im})
\end{aligned}
\end{aligned}
$$




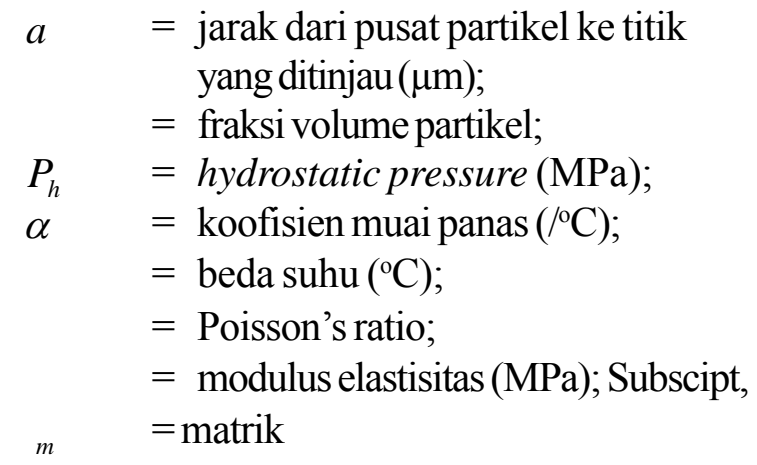

Flexural modulus atau modulus elastisitas (E) pada pengujian bending ini(E) dihitung dengan menggunakan persamaan (Bassin, 1979).

$$
E=\frac{F_{\text {fail }} \cdot l}{24 . \delta . I}\left(3 L^{2}-4 l^{2}\right)
$$

\section{dimana :}

$$
\begin{array}{ll}
F_{\text {fail }} & =\text { pembebanan }(\mathrm{N}) ; \\
l & =\text { jarak tumpuan ke gaya tekan }(\mathrm{mm}) ; \\
\delta & =\operatorname{defleksi}(\mathrm{mm}) ; \\
& =\text { momen inersia }\left(\mathrm{mm}^{4}\right) ; \\
L & =\text { jarak kedua tumpuan }(\mathrm{mm})
\end{array}
$$

\section{METODE PENELITIAN}

Matrik $\mathrm{Al}_{2} \mathrm{O}_{3}$ berukuran 60 ìm (Brataco Chemical) mengandung $20 \%$ berat silica dengan ukuran $1 \mu \mathrm{m}$ (Swithzerland) sebagai matrik. Partikel penguat digunakan chromium ukuran $300 \mu \mathrm{m}$ (Merc-jerman). Pembuatan keramik dilakukan melalui beberapa tahap yaitu: mixing (pencampuran); pressing (pengempaan) dan sintering ( pamanasan)

Peralatan yang dipergunakan; cetakan specimen, mixer, timbangan digital, furnace, alat uji vickers dan mikroskop optic.

\section{HASIL DAN PEMBAHASAN}

Pengujian densitas dilakukan dengan menggunakan teori Archimedes, dimana spesimen ditimbang di udara $\left(\mathrm{W}_{\text {udara }}\right)$ dan ditimbang di dalam air murni $\left(\mathrm{W}_{\text {fluida }}\right)$. Penimbangan di dalam air ini menyebabkan beratnya akan berkurang sebesar berat fluida (air) yang dipindahkan.

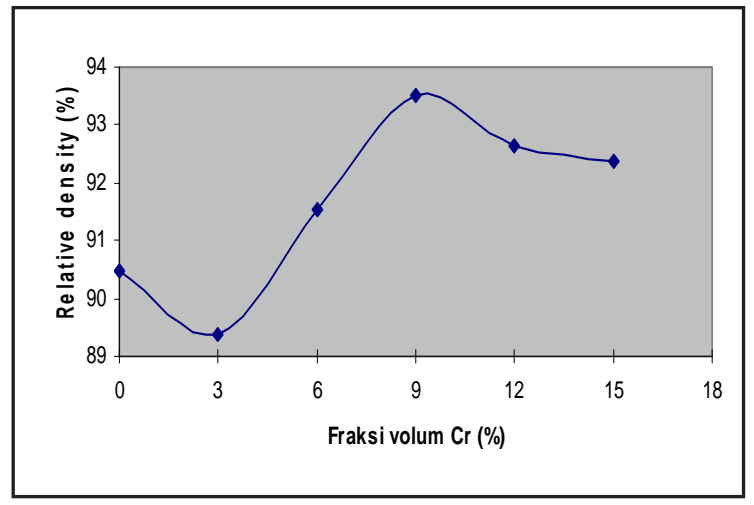

Gambar 1. Hubungan antara Relative Density dengan Fraksi Volume Partikel Cr pada Spesimen yang Disinter pada Suhu $1450^{\circ} \mathrm{C}$

Secara umum densitas relatif semua komposisi komposit yang disinter pada suhu $1450^{\circ} \mathrm{C}$ masih tergolong rendah (kurang dari 95\%) sebagaimana ditunjukkan pada Gambar 1. Penyebab rendahnya densitas ini kemungkinan adalah karena ukuran partikel alumina teknis sebagai matrik tergolong besar $(60 \mu \mathrm{m})$. Penyebab lainnya adalah suhu sinter yang belum optimum karena keterbatasan kemampuan furnace yang ada. Ukuran partikel merupakan salah satu faktor penting dalam sintering (Barsoum, 1997).

Analisa perhitungan thermal stress dilakukan dimana sebuah partikel bulat dalam sebuah infinite matrix, maka besarnya thermal stress dapat dihitung dengan persamaan (2). Koefisien muai panas alumina yang mengandung $20 \%$ berat silika yang dihitung dengan persamaaan rule of mixture diperoleh $5,1 \times 10^{-6} /{ }^{\circ} \mathrm{C}$, koefisien muai panas teoritis $\mathrm{Cr}$ adalah $6,5 \times 10^{-}$ ${ }^{6} /{ }^{\circ} \mathrm{C}$, poisson's ratio alumina yang mengandung $20 \%$ berat silika yang dihitung dengan persamaan rule of mixture diperoleh 0,22 . Poisson's ratio teoritis $\mathrm{Cr}$ adalah 0,21, modulus elastisitas alumina yang mengandung $20 \%$ berat silika dihitung dengan persamaan (6) diperoleh 13,68 $\mathrm{GPa}$, modulus elastisitas teoritis Cr adalah 279 $\mathrm{GPa}$,jarak pada matrik dari interface (r) diambil 0 , perbedaan temperatur $(\Delta \mathrm{T})$ akibat pendinginan dari suhu sintering sebesar $-1425^{\circ} \mathrm{C}$.

TabelHasil perhitungan tegangan sisa yang terjadi pada interface antara matrik dan partikel 


\begin{tabular}{|c|c|c|c|c|}
\hline \multirow{2}{*}{$\begin{array}{c}\text { Kandungan } \\
\text { Cr }\end{array}$} & \multirow{2}{*}{$\begin{array}{c}\text { Tegangan } \\
\text { sisa partikel } \\
(\mathrm{MPa})\end{array}$} & \multicolumn{2}{|c|}{$\begin{array}{c}\text { Tegangan sisa pada } \\
\text { matrik (MPa) }\end{array}$} & $\begin{array}{c}\text { Jari- } \\
\text { jari } \\
\text { kritis } \\
(\mu \mathrm{m})\end{array}$ \\
\cline { 3 - 4 } & Radial & Tangensial & \\
\hline 0\% volum & 0 & 0 & 0 & 0 \\
\hline $3 \%$ volum & 43,3 & 43,3 & $-23,7$ & 30,3 \\
\hline $6 \%$ volum & 41 & 41 & $-24,4$ & 32,3 \\
\hline $9 \%$ volum & 38 & 38 & $-24,6$ & 33,9 \\
\hline $12 \%$ volum & 36,5 & 36,5 & $-25,7$ & 35,5 \\
\hline $15 \%$ volum & 34,5 & 34,5 & $-16,4$ & 37,5 \\
\hline
\end{tabular}

Dari hasil perhitungan bahwa kondisi komposit dimana matrik< partikel hal inimenyebabkan tegangan radial tensile sedangkan tegangan tangensial compressive (Barsoum, 1997).

\section{PENGUJIAN KEKERASAN}

Pengujian kekerasan dilakukan pada spesimen berbentuk silindris yang di sinter pada suhu $1450^{\circ} \mathrm{C}$. Spesimen yang telah disinter dan diukur densitasnya, kemudian di-mounting dalam resin untuk memudahkan pemolesan dan pengujian kekerasan.

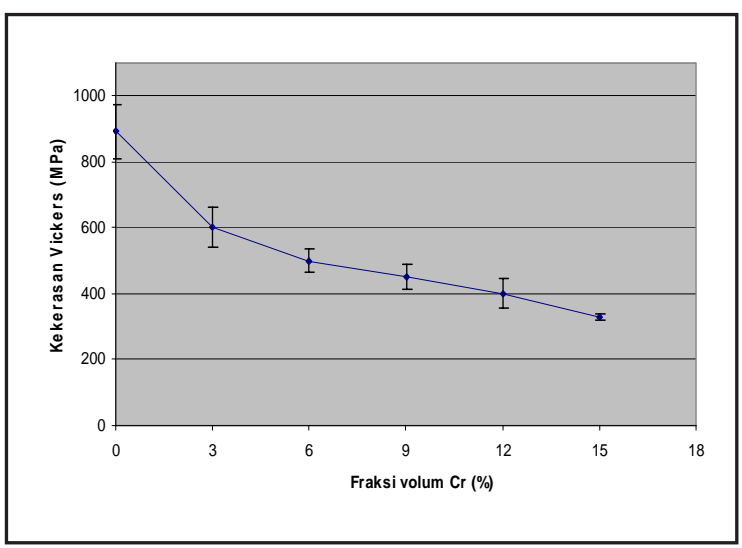

Gambar 2. Hasil Pengujian Kekerasan Vickers

Setiap spesimen dilakukan enam titik pengujian pada permukaan penampangnya dengan beban 153,2 N menggunakan mesin uji kekerasan Vickers makro. Diagonal diamati dengan menggunakan mikroskop optik dengan pembesaran 100 kali dimana 38 garis pada pembacaan mikroskop sama dengan $1 \mathrm{~mm}$ pada spesimen.
Berdasarkan hasil eksperimen yang ditunjukkan pada Gambar 3 terlihat bahwa harga kekerasan Vickers pada matrik tanpa penambahan partikel penguat $\mathrm{Cr}$ lebih rendah jika dibanding dengan harga kekerasan teoritisnya sebesar 19 Gpa (Barsoum, 1997), hal ini kemungkinan oleh tingginya porositas spesimen. Sebagaimana dijelaskan di muka bahwa tingginya porositas tersebut kemungkinan disebabkan oleh ukuran partikel yang besar $(60 \mathrm{~m})$ dan suhu sinter yang masih rendah.

Pada pengujian kekerasan Vickers pada Gambar 2 juga dapat dilihat bahwa dengan penambahan partikel $\mathrm{Cr}$ ke dalam matrik keramik mengakibatkan kekerasannya menurun dari $892 \mathrm{MPa}$ (tanpa penguat $\mathrm{Cr}$ ) menjadi 329 $\mathrm{MPa}(15 \%$ volum $\mathrm{Cr})$ atau kekerasannya mengalami penurunan sebesar $63 \%$ hal ini disebabkan karena kekerasan teoritis logam Cr jauh lebih kecil dibanding kekerasan teoritis alumina.

\section{PENGAMATAN STRUKTUR MIKRO}

Bentuk porositas pada permukaan spesimen dapat dilihat pada Gambar di bawah ini, terlihat dengan jelas porositas pada specimen masih cukup besar. Sebagaimana dijelaskan dimuka bahwa besarnya porositas tersebut kemungkinan disebabkan oleh ukuran partikel yang besar (60) dan suhu sinter yang belum memadai.

Keramik

\section{SIMPULAN}

Berdasarkan hasil penelitian yang telah dilakukan dapat disimpulkan sebagai berikut: 
relative density tertinggi sebesar diperoleh pada komposit dengan $9 \%$ volume $\mathrm{Cr}$ yang disinter pada temperatur $1450^{\circ} \mathrm{C}$; harga kekerasan
Vickers turun seiring dengan penambahan partikel Cr; porositas pada specimen masih culup tinggi.

\section{DAFTAR PUSTAKA}

Anderson, J.C., Leaver, K.D., Rawlings, R.D., Alexander, J.M., 1990, Material Secience, Chapman and Hall, 2-1 Boundary Row, London SE1 8HN, UK.

Borsoum, M., 1997, Fundamentals of Ceramics, Mc Graw-Hill Companies, New York.

Becher, P.F and Warwick, W.H., 1993, Factors Influencing The Thermal Shock Behavior of Ceramics, Nato ASI Series; Series E: Thermal Shock and Thermal Fatique Behaviour of Advanced Ceramic, vol. 241.

Bassin, M.G., Brodsky, S.M., and Wolkoff, H., 1979, Statics and strenght of Materials, Third Edition, Greeg Division Mc Graww-Hill Book Company.

Chawla, K.K., 1993, Ceramic Matrix Composites, University Press, Cambridge, Great Britain.

Davidge, R.W. dan Green,T.J., 1968, The Strength of Two-Phase Ceramic/Glass Material, Journal of Material Science 3, 629-634.

Ekstrom,T., 1992, Alumina Ceramics with Particle Inclusions, Journal of the European Ceramic Society 11(1993) 487-496.

Fahmi, H., 2004, Thermal Shock Resistance Komposit Matrik Alumina (mengandung $20 \%$ berat $\mathrm{SiO}_{2}$ ) yang diperkuat Partikel Chromium, Tesis Magister Jurusan Teknik Mesin Fakultas Teknik UGM, Yogyakarta.

Guichard, J.L., Tillement. O, Mocellin. A., 1997, Preparation and Characterization of Alumina-Iron Cermets by hot-Pressing of Nano Composite Powder, Journal of Materials Science 32, 4513-4521.

German, R.M., 1984, Powder Metallurgy Science, Metal Powder Industries Federation, New Jersey.

Green, D.J., 1998, An Introduction to the Mechanical Properties of Ceramics, Cambridge University Press.

Indra, A., 2003, Pengaruh Penambahan Partikel Nickel terhadap Sifat Fisis dan Mekanis Alumina yang mengandung 20\% berat silika, Tesis Magister Jurusan Teknik Mesin Fakultas Teknik UGM, Yogyakarta.

Kondo, H., Sekino, T., Choa and Niihara, K.,1999, Mechanical Properties of 3Y-ZrO$/ \mathrm{Ni}$ Composite Prepared by Reductive Sintering, Publications of the Ceramics Society of Japan vol. 2, 419-422.

Kingery, W.D., Bowen, H.K., Uhlmann, D.R., 1975, Introduction to Ceramics, A Wiley Interscience Publication Jonh Wiley and Sons, New York. 
Nindhia, T.G., 2003, Peningkatan Ketangguhan Retak Bahan Tahan Api Berkadar Alumina Tinggi dengan Penambahan Whisker Silikon Karbida, Desertasi Doktor Jurusan Teknik Mesin Fakultas Teknik UGM, Yogyakarta.

Ryshkewitch, E., 1960, Oxide Ceramic, pp.44-45, Academic Press, New York.

Ronald., F., Gibson, Principle of Composite Material Mechanics, MC Graw Hill, inc., 1994.

Surdia T., dan Saito, 1992, Pengetahuan Bahan Teknik, Pradnya Paramita, Jakarta.

Somiya S., 1989, Advanced Technical Ceramics, Academic Press inc, Tokyo.

Van Vlack, L.H., 1985, Elements of Materials Science an Engineering, Addison Wesley Publishing Company, New York.

Yanagida, H., 1996, The Chemistry of Ceramics, John Wiley and Sons, New York. 